firmly believe, have prevented this terible calamity-i.e., the syphiliric infection of the wife; and I would now humbly suggest to all who undertake 1 he treatment of venereal disease, that if they have a cerrainty that their patients will remain celib te all their live: they may heal ap their sores and dispel their eruptions aud sore throats in any manner they like; but that they hive no $i i_{2}$ ht to ex. pose the pure, innoceut, high-minded females of society to contamination by marrying men treated without mercury."

\section{A CASE OF TRANSPOSITION OF HEART.} BY CHAS. POPE, L.R.C.P. \& L.R.C.S. EDIN.

G. C_- a bicklayer, aged forty-one, was admitted to the South Shields Workhouse Hospital on May 24:h, 1882, suffering from pneumonia with distressing dyspnces and extreme lividity. The heart's impulse could not be detected anywhere on the left side of the sternum, and the sounds on auscultation were distant and muffled. On examining the right side I found the impulse well marked about two iuches below the right nipple and two inches on the right of the sternum. Oa auscultation at this point I heard a mitral regurgitant murmur, which, however, was only audible over a very limited space, ahout two inches in diameter. It conld not be heard in the axilla nor at the lower angle of either scapula. The pulsarions could be heard feebly at the back of the right chest low down, but were inaudinle at the back of the left. I could obtain no history of pleurisy, empyema, or pericarditis, neither was there any evidence of tumour of any description, the man declaring that until the present he had never had a day's illness in his life. He had always been a hard worker and a good deal addicted to drink. Under the circumstances $I$ was driven to the conclusion that this was a case of transposition of heart.

The patient died on June 4th, and on the following day, assisted by Mr. Robson, I made a post-mortem examination. On opening the thorax we found the heart vatural in size and weight, but nearly entirely on the right of the median line, as indicated during life. The aorta ascended to the central part of the thorax, after which it arched at the usual level over to the left, and descended on the $l+f t$ of the vertebral column, giving off in their normal position its three large branches ; these were distributed as usual. The pericardium was nowhere adherent. On opening the left side of the heart the anterior flap of the mitral valve was partially adberent to the endocardium, as were also some of the chordæ tendineæ, thus preventing its proper closure, and giving rise to regurgitation; there was also slight fibrous thickening. The tricuspid valve was in every respect normal, but the right side of the heart was full of clotted venous blood. The lungs in appearance and on section presented the usual signs of grey hepatisation; the right luug was markedly smaller than the left, but consisted of three lobes the left lung consisted of two lobes as usual ; there was no fluid in the cavity of the pleura, nor were there any pleuritic adhesions. On opening the abdomen the liver was found in its natural position and healthy, as were all the other organs. This was evidently a case of congenital abnormality.

South Shields.

\section{DISLOCATION OF THE LOWER END OF THE TIBIA FORWARDS OR OF THE FOOT BACKWARDS.}

\section{By GEO. ASHMEAD, L.R.C.P. \& L.R.C.S. EDIN.}

ON the evening of June 11th I was sent for in haste to the house of an ironworker, who was said to have broken his leg. I found him lying on the sofa with his left leg resting upon its fellow; he was groaning with pain, and on examination I found the lower end of the tibia occupying a position on the instep of the foot; the extensor muscles and the integuments were tightly distended and of a rose-red colour; the toes pointed downwards and the heel drawn upwards. The fibula was fractured near the articulation. By securing the knee and extending the foot with slight flexion on the tihia, reduction was easily effected without the aid of an anæsrhetic, accompanied by a grating sout distinctly audible to those present. Instant relief followed replacemeut; the fuot was bandaged and light lateral splints appled. The easv reduction may be ascribed to the early artunlance, the injury having taken place only a quarter of an hour previou*ly. The ahove is the only example I have met with, and is described by Bryant, Hamilton, and others as extremely rare. Some surgeons have found it very difficult of reduetion. The patient had a pair of heavily nailed boots on, and slipped npou some wet glazed bricka, his leg being doubled under him, "tailor fashiun," to use his own words. Brierley Hill.

\section{d ettirtor}

\section{HOSPITAL PRACTICE, BRITISH AND FOREIGN.}

Nulla autem est alia pro certo noscendi via, nisi quamplurimas et morboram

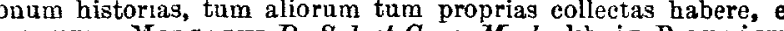
inter se comparare.-Mongagmi De Sed. et Caus. Morb, lib. iv. Procmium.

\section{MIDDLESEX HOSPITAL}

CASES OF SARGOMA.

\section{(Under the care of Mr. J. W. HuLKE.)}

CASE 1. Sarcoma beneath the Superficial Muscles of the Calf of the Leg; Excision; Recurrence; Amputation; Secundary Hcemorrhage; Death.-A cook, aged sixty-nine, was admitted into Regent ward on April 26th, 1880, with a swelling in the right ley, which she thought had begun six years previously. Latterly its growth had been rapid, and it had become very painful. The swelling was eaused by an elastic, lobulated mass, reaching from near the heel halfway to the ham. When the leg was extended the mass appeared fixed, but when the leg was flexed, and the super. ficial muscles of the calf were relaxed, the mass was found to be so movable as to preclude the idea of its being attached to periosteum and bone. Amputation being rejected by the patient, on May 5th it was cut out by a long incision, splitting the gastrocnemius and soleus. It was found to be beneath the fascia covering the tibialis pusticus muscle. The posterior tibial artery passed into the tunour, and was necessarlly cut away with it; the posterior tibial nerve, which was stretched over its surface, was disengaged from it and saved. The wound was washed out with a cbloride of ziac solution, and dressed with boric lint, and the limb was slung. Healing was slow, as might be expected at the patient's age, and in so extensive a wound, and was not complered till the end of July.

In the following October the patient was readmitted with a recurrence of the tumour. There was now above the inner malleolus a mass of the size of a small orange. The skin over its summit was gangrenous, and for some space around it was inflamed. She complained of much pain in the foot, and plauring it on the ground caused spasmndic flexure of the leg and foot. Amputation, previously rejected, was now sought by the patient, and on Oct. 13tu, the limb was removed by Teale's method, below the knee. The vessels were secured with carbolised eatgut ligatures. At the end of one week she had very severe bæmorrhage from the stump, from which she never rallied, and died eight hours later. The primary and recurrent tumours were spindlecelled sarcomata.

CASE 2. Sarcomatous (?) Tumour of Scapula; Secondary Affection of the Lungs. - A housekeeper, aged forty-four, was admitted into Regent ward in September, 1881, for a tumour of the right shoulder-blade. It was an oval mass, of the size and figure of a cocoa-nut cut lengthwise, firmly attached to the scapula. Its surface was even and defined, and the skin over it was free. It was not teuder when handled, but occasioned severe pain, radiating into the neck and down the arm. The grasping power of the right hand was less than that of the left, and the hand felt numb. No enlarged glands could be felt in the armpit. Her breath was short, and she had a cough. She attributed the origin of the tumour to a fall five months before, and she said that it had grown from the size of a walnut to its present bulk during 